\title{
Estimation of monthly global solar radiation in Buenos Aires: preliminary analysis.
}

\author{
Susan G. Lakkis, Mario Lavorato, Pablo O. Canziani
}

Facultad de Ciencias Agrarias, Pontificia Universidad Católica Argentina (UCA), Equipo Interdisciplinario para el Estudio del Cambio Global (PEPACG), Pontificia Universidad Católica Argentina (UCA), Argentina.

$$
\begin{aligned}
& \text { gabylakkis@uca.edu.ar; gabylakkisetul@gmail.com } \\
& \text { División Radar Laser, DEILAP (CITEDEF - CONICET), Argentina }
\end{aligned}
$$

Equipo Interdisciplinario para el Estudio del Cambio Global (PEPACG), Pontificia Universidad Católica

Argentina (UCA); Consejo Superior de Investigaciones Científicas y Técnicas (CONICET)

\begin{abstract}
Six existing models and one proposed approach for estimating global solar radiation were tested in Buenos Aires using commonly measured meteorological data as temperature and sunshine hours covering the years 2010-2013. Statistical predictors as mean bias error, root mean square, mean percentage error, slope and regression coefficients were used as validation criteria. The variability explained $\left(R^{2}\right)$, slope and MPE indicated that the higher precision could be excepted when sunshine hours are used as predictor. The new proposed approach explained almost $99 \%$ of the $R_{G}$ variability with deviation of less than $\pm 0.1 \mathrm{MJm}^{-2}$ day $^{-1}$ and with the MPE smallest value below $1 \%$. The well known Angström-Prescott methods, first and third order, was also found to perform for the measured data with high accuracy $\left(R^{2}=0.97-0.99\right)$ but with slightly higher MBE values $\left(0.17-0.18 \mathrm{MJm}^{-2} \mathrm{day}^{-1}\right)$. The results pointed out that the third order Ångström type correlation did not improve the estimation accuracy of solar radiation given the highest range of deviation and mean percentage error obtained. Where the sunshine hours were not available, the formulae including temperature data might be considered as an alternative although the methods displayed larger deviation and tended to overestimate the solar radiation behavior.
\end{abstract}

\section{Indexing terms/Keywords}

Monthly solar radiation, meteorological data, statistical predictors, Argentina.

\section{Academic Discipline And Sub-Disciplines}

Atmospheric Environment, Renewable energy

\section{SUBJECT CLASSIFICATION}

Solar radiation, solar-terrestrial physics

\section{TYPE (METHOD/APPROACH)}

Ångström-Prescott methods, empirical estimation, regression coefficients.

\section{Council for Innovative Research}

\author{
Peer Review Research Publishing System
}

Journal: Journal of Advances in Physics

Vol 5, No.1

japeditor@gmail.com 


\section{INTRODUCTION}

Solar radiation, the primary natural energy source, has an irreplaceable role to play in the energy balance of the EarthAtmosphere system. In fact, due to global radiation arriving on the ground driving physical, chemical and biological processes, data on the Earth's surface are required in many research and application fields such as hydrological and soil-vegetation-atmosphere transfer processes, agricultural and meteorological studies, ecology, architecture and environment, among others [1,2].

Moreover, the availability of these data, or their estimation based on specific sites or mechanistic prediction models, improves the usefulness of the climate data sets [3]. The study of surface solar radiation can also be an instrument of great relevance to detect changes in the atmosphere composition. Authors like Stanhill and Cohen [4], Wild et al. [5] or Mishchenko et al. [6], among others, have shown in their works that solar radiation studies revealed global dimming and brightening trends on decadal scales, affecting climate change processes. However there is a dearth of complete recorded data throughout the years in most areas of the world. Insufficient or restricted data were reported by several authors in many countries [7,8]. In spite of its significance, current radiation measurements are sparsely instrumented over the world compared to other meteorological variables.

In order to estimate the surface solar radiation at any location with the best possible accuracy, several techniques, with different degree of complexity, have been explored during past decades. Analysis with interpolation methods [9] , multivariate stochastic processes [10,11], satellite based methods [12], estimation from substituted data from nearby stations [13] as well as empirical models have been considered for estimating solar radiation data. Notwithstanding, remote sensing data are still scarce in some areas, also only being available for limited periods of time. In addition, the low sampling frequency and coarse spatial resolution of these methods does not make them suitable for site specific application together with a limited precision $[12,14]$. Stochastically generated data are useful for exploring possible model scenarios long-term simulations, but the method is still not capable of generating data that would match the actual weather at particular time of interest [8], although multi-site generation of weather data methods are being now tested. The solar radiation data obtained using data from nearby stations must consider the threshold distance so as far to be results with acceptable precision, considering season and topography factors.

On the other hand, empirical methods involving a set of equations to estimate solar radiation have the advantage that the operational parameters required for estimation are meteorological variables observed and available within the site, allowing its widespread application. The parameters, frequently used as predictors of atmospheric parameters, usually are sunshine duration, cloud cover, ambient temperature, relative humidity, and precipitation data. This kind of model is also called meteorological model and, depending on the relationship between global solar radiation and the atmospheric predictor, the models can be roughly divide into three categories; i.e. cloud-based models [15, 16], sunshine-based models $[17,18]$ and temperature based models $[19,20,21]$

Quite a number of studies were carried out with empirical relationships and the results obtained showed that the highest accuracy is generally to be expected when sunshine based method is used, instead of those based on temperature or clouds parameters. They also noted that solar radiation estimations could be improved when the models use more parameters in their equations and are locally calibrated, since the global solar radiation is strongly dependent on the local meteorological variables. However, this hypothesis must be in-situ tested and local analyses appear to be essential.

Nonetheless, not much work has been done with regards to solar radiation in Buenos Aires, even though some efforts have been made for different parts of the country; i.e., La Pampa [22], Córdoba [23]. In fact, to the best of our knowledge, there is no published record of in situ measurements over Buenos Aires. In order to fill this gap, the aim of this study was to evaluate different empirical models for the estimation of the monthly average daily solar radiation on a horizontal surface. The tested methods were chosen depending on the availability of the datasets required by the set of equations under evaluation. The results thus derived from the analysis of the meteorological data from 2010-2013 of Buenos Aires, were compared. Finally, and in light of the results, an exponential parameterization is proposed for predicting the monthly solar radiation. The paper is organized as follows: datasets and methodology, including a brief description of the current methods used, are in the next section. Section 3, deals with the results derived from different approaches. Conclusions are given in Section 4.

\section{DATA AND METHODS}

\subsection{Data}

Buenos Aires is located on the western shore of the Río de la Plata, on the continent's southeastern coast. The site has a warm humid temperate climate with hot summers and no dry season. The area within 25 kilometers of the place of measurements is covered by oceans and seas (43\%), croplands $(24 \%)$, built-up areas (19\%), floodplains (9\%), and grasslands (4\%). Over the course of a year, the temperature can range from $7^{\circ} \mathrm{C}$ to $28^{\circ} \mathrm{C}$, although it is not uncommon finding days with temperatures below $3^{\circ} \mathrm{C}$ or above $35^{\circ} \mathrm{C}$ in the recent decade. The warm season extends from late November to middle March with daily high temperature above $27^{\circ} \mathrm{C}$ in average while the cold season goes from May to August with an average daily maximum temperature below $16^{\circ} \mathrm{C}$. The relative humidity typically ranges from $40 \%$ to $90 \%$. Over the entire year, the typical forms of precipitation are basically thunderstorms (40\%) and moderate rain.

The meteorological data used in this study were collected from two data source far between less than $10 \mathrm{~km}$. The Servicio Meteorológico Nacional (SMN) provided the sunshine hours data while solar radiation ( $\pm 5 \%)$, atmospheric pressure $( \pm 0.2 \mathrm{hPa})$, temperature $\left( \pm 0.2^{\circ} \mathrm{C}\right)$, the direction and speed of winds $( \pm 0.5 \mathrm{~m} / \mathrm{s})$ and precipitation $( \pm 0,5 \%)$ have 
been regularly measured by the automatic weather station operated by the "Equipo Interdisciplinario para el Estudio de Procesos Atmósféricos en el Cambio Global (PEPACG)", Pontificia Universidad Católica Argentina in the vicinity of the Buenos Aires harbour, near its southern end at $50 \mathrm{~m}$ amsl $(-34,61 \mathrm{~S},-58,36 \mathrm{~W})$, with a sampling frequency of $0.003 \mathrm{~Hz}$, from midnight to midnight $(24 / 24 \mathrm{~h})$ recorder at 5 -min intervals. Based on the measured data, an integrated dataset including both data sources was established with 302400 available observations belonging to the period July, 2010January, 2013. Hourly solar radiation measurements were integrated to daily values and then averaged monthly. The quality control of the values was applied considering physical and statistical criteria; i.e., the higher boundary of measured solar radiation were imposed considering that the global solar radiation measured on a horizontal surface at the Earth's surface has to be lower than the extraterrestrial solar radiation incident and cannot be high in rainy days [24]. As Geiger et al. [25]. proposed, solar radiation values $\left(R_{G}\right)$ equal or higher than $3 \%$ of the extraterrestrial value ( $\left.R_{\text {ext }}\right)$ incident on horizontal surface, in case of hourly and daily cumulative data were considered as lower limit of the measured data set. Data that failed this quality control were excluded from the final database. Table 1 shows the number of missing data and the corresponding unit of each item. Trnka et al. [26] proposed in their work an interesting way to show the relationship between the measured data and the quality criteria by plotting the distribution of the observed data, grouped at predefined intervals, plus the incident global solar radiation $\left(R_{G}\right)$ vs extraterrestrial radiation $\left(R_{\text {ext }}\right)$ ratio distribution. Similarly, the distribution of our observed $R_{G}$ values, plotted at $2 \mathrm{MJm}^{-2}$ day $^{-1}$ predefined intervals is shown in Figure 1 . The six intervals show that most of the data is in the $15-30 \mathrm{MJm}^{-2}$ day $^{-1}$ range. Daily total extraterrestrial radiation, also known as Angot radiation was calculated as a function of latitude, day of year, solar angle and solar constant (1367W $\mathrm{m}$ ${ }^{2}$ ) according to Allen et al. [27].

\begin{tabular}{|l|l|l|}
\hline Variable & Missing data & Unit \\
\hline Measured daily global solar radiation & 22 & $\mathrm{Mjm}^{-2}$ \\
Sunshine hours & 0 & Hour \\
Measured daily (maximum/ minimum) temperature & 0 & ${ }^{\circ} \mathrm{C}$ \\
Measured daily precipitation & 0 & $\mathrm{~mm}$ \\
Measured daily pressure & 0 & $\mathrm{hPa}$ \\
Wind speed & 0 & $\mathrm{~m} / \mathrm{s}$ \\
\hline
\end{tabular}

Table 1. Meteorological measured data from 2010-2013 at Buenos Aires provided by SMN plus own source

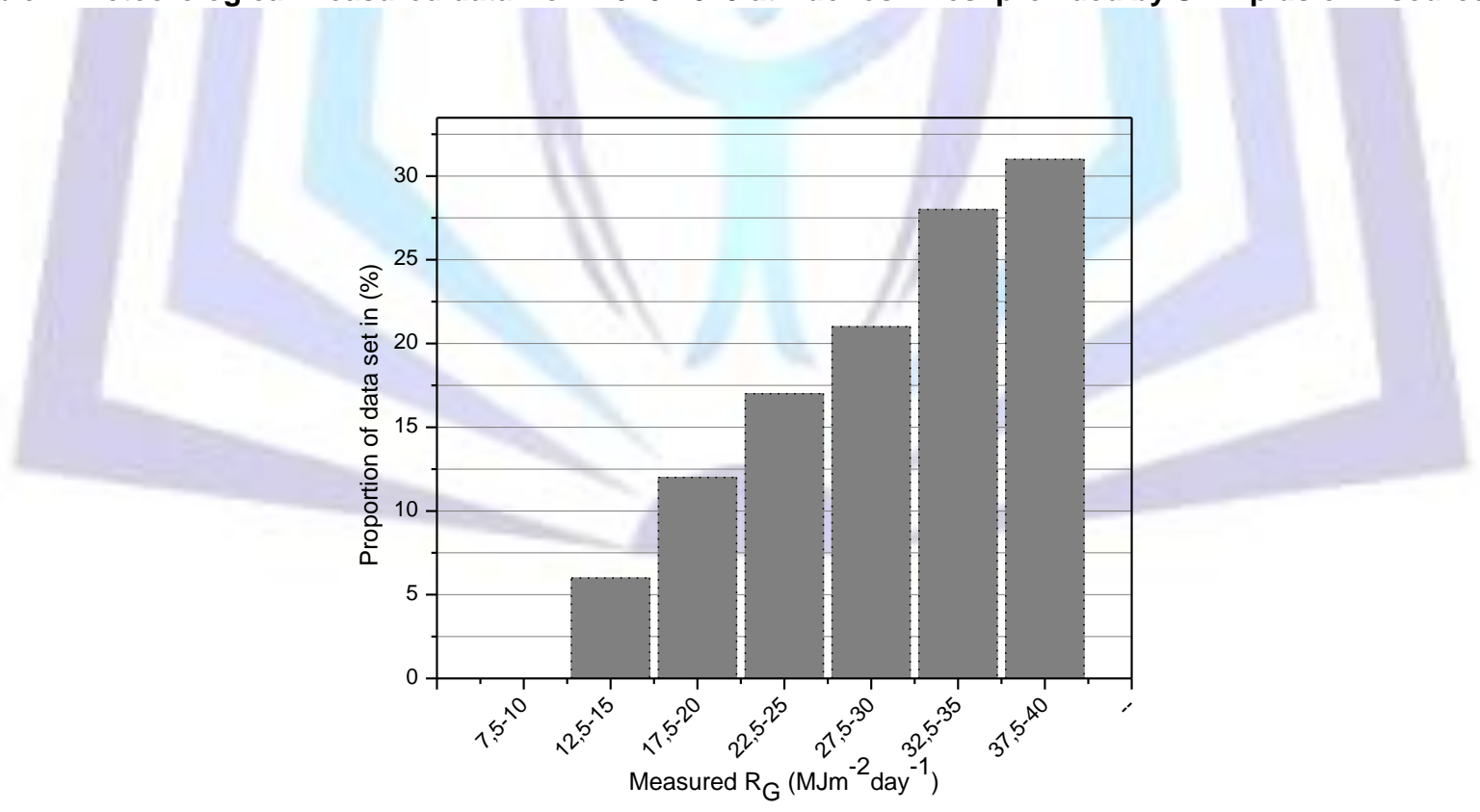

Figure 1. Distribution of observed monthly $R_{G}$ within predefined intervals

\subsection{Methods}

The underlying approach in most existing global radiation estimation methods is to express solar radiation reaching the Earth surface as function of extraterrestrial radiation, each empirical approach being distinctive through the meteorological parameters involved. 
Brief descriptions of the models employed in this analysis are as follows:

a) The Ångström model (AP).

Ångström (1924) developed a simple model for estimating solar radiation reaching the Earth based on the linear relationship between radiation and sunshine hours. The first version of this formula was available only for sites with radiation data. Prescott in 1940 [18] proposed an improved version where the solar radiation is based on a fraction of extraterrestrial radiation derived from sunshine hours and the day length:

$$
R_{G}=R_{e x t}\left(a+b \frac{n}{N}\right)
$$

where $\mathrm{n}$ is the sunshine duration (hours), $\mathrm{N}$ the maximum possible sunshine duration (hours) and the coefficients "a" and "b" are site-independent. The physical significance of the regression coefficients is that "a" represents the case of overall atmospheric transmission for an overcast sky condition, while " $b$ " is the rate of increase of $R_{G} / R_{\text {ext }}$ with $n / N$. The sum $(\mathrm{a}+\mathrm{b})$ represents the overall transmission under clear sky condition. Equation 1 is also known as first order Ångström correlation (AP). Angström suggested values of 0.2 and 0.5 for empirical coefficients "a" and "b" respectively. Other authors have calibrated this expression for different places and found they vary significantly as Doorenbos and Pruitt [28] showed.

The following second (AP2) and third (AP3) order expressions are as follows:

$$
\begin{gathered}
R_{G} / R_{e x t}=a+b\left(\frac{n}{N}\right)+c\left(\frac{n}{N}\right)^{2} \\
R_{G} / R_{e x t}=a+b\left(\frac{n}{N}\right)+c\left(\frac{n}{N}\right)^{2}+d\left(\frac{n}{N}\right)^{3}
\end{gathered}
$$

where $a, b, c$ and $d$ are the regression coefficients.

b) The Hargreaves \& Samani model (HS)

Another relatively simple method of estimating solar radiation was proposed by Hargreaves and Samani [29] based on a linear regression between the clearness index and the square root of the temperature difference:

$$
R_{G}=R_{e x t}\left(a+b \Delta T^{0.5}\right)
$$

where $\Delta T$ is the air thermal amplitude (daily or monthly), with "a" and "b", the regression constants. The authors proposed equation (4) to estimate RG on a monthly basis; however it also works well on a daily basis [30].

c) Allen model $(\mathrm{A})$

The so called Allen model is a special type of Hargreaves model. If the coefficient "a" becomes equal to cero, then the relationship of Hargreaves turns to a simply equation based on air temperature difference values. Consider

$$
R_{G}=R_{e x t}\left(b \Delta T^{0.5}\right)
$$

with b empirical coefficient.

d) García model (G)

García in 1994 introduced a slight modification in the AP model, considering the maximum number of sunshine hours or day length $(\mathrm{N})$. If $a$ and $b$ are the empirical coefficients:

$$
R_{G}=R_{e x t}\left(a+b \frac{\Delta T}{N}\right)
$$

e) Annandale model (AN)

The modified Hargreaves-Samani model developed by Annandale et al. [31] includes a correction for altitude (Z), as follows:

$$
R_{G}=R_{\text {ext }}\left\lfloor a\left(1+2.7 \times 10^{-5} Z\right)(\Delta T)^{1 / 2}\right\rfloor
$$

where "a" is an empirical coefficient.

f) Exponential new Parametrization (NP) 
As an alternative to conventional approaches, the following exponential equation based on the sunshine hours and the maximum possible sunshine duration hours, was successfully applied to solar radiation estimation:

$$
\left.R_{G}=R_{e x t}\left[a e^{\frac{n N}{b}}+c\right)\right]
$$

where "a", "b" and "c" are the regression coefficients, $\mathrm{n}$ is the sunshine duration (hours) and $\mathrm{N}$ the maximum possible sunshine duration (hours).

Using the preceding relationship (1) - (7), solar radiation is supposed to be calculated for any point in the earth's outer atmosphere for each day of the year as a function of latitude and solar declination. However, gases and clouds introduce changes to both magnitude and spectral composition of solar radiation.

\subsection{Performance indicators}

Agreement between predicted and measured values was tested using the Nash Sutcliffe coefficient (NSE) also known as coefficient of determination $\left(R^{2}\right)$ of the regression line between predicted and measured values, providing information about the variability explained by the tested method, slope of regression line including regression function forced through origin, the mean bias error (MBE), root mean square error (RSME) and the mean percentage error (MPE). A model is more efficient if $R^{2}$ is closer to 1 . While the MBE provides information on long-term performance of the models under consideration and can be understood as an indicator of systematic error, the test on RSME gives an idea of the magnitude of the non-systematic error and provides information on the short-term performance of the models as it allows a term by term comparison of the actual deviation between the predicted value and the observed one. A positive MBE value usually shows a model overestimation while a negative value a underestimation. The MPE is an overall measure of forecast bias, computed from the actual differences between a series of forecasts and actual dataset observed. As Almorox showed, [32] the disadvantage associated with MPE and MBE is that values with different signs may cancel each other. However, low values of both parameters are desirable, even when the over or the underestimation could be due to few values in the dataset.

The MBE, RMSE (in MJm ${ }^{-2}$ day $^{-1}$ ), NSE, and MPE (\%) performance indicators, calculated for each month of each year as well as for the whole period considering the whole series of $R_{G}$ expressed in $\mathrm{MJm}^{-2}$ day $^{-1}$, can be calculated as follows:

$$
\begin{gathered}
R^{2} \equiv N S E=1-\frac{\sum\left(Q_{o b s}-Q_{p r e}\right)^{2}}{\sum\left(Q_{o b s}-\bar{Q}\right)^{2}} \\
M B E=\frac{\sum\left(Q_{o b s}-Q_{p r e}\right)}{N_{o b s}} / \mid \\
R M S E=\sqrt{\frac{\sum\left(Q_{o b s}-Q_{p r e}\right)^{2}}{N_{o b s}}} \\
M P E=\frac{100}{N_{o b s}}\left(\frac{\sum Q_{o b s}-Q_{p r e}}{Q_{o b s}}\right)
\end{gathered}
$$

where $Q_{o b s}$ is the measured value, $Q_{\text {pre }}$, the estimated value, $\bar{Q}$ is the average value of the observed radiation, and $\mathrm{N}_{\text {obs }}$ the number of data.

\section{RESULTS AND DISCUSSION}

By means of different existing empirical approaches we estimated the monthly average daily global solar radiation in Buenos Aires during July, 2010-January, 2013. Figure 2 shows the comparison between monthly mean of predicted and the observed global radiation for all the methods. A simple inspection of the figure allows noting that the estimated values derived for $R_{G}$ exhibit a good variation trend along with the observed values; thus the seven tested approaches were able to reproduce $R_{G}$ data and in general fitted well both the patterns and values of the observed data. 
Using the technique of least square regression, regression equations were developed based on Eqs. (1) - (8). The fitted coefficients are shown in Table 2. The performance of the eight models (Eqs. (1) - (8)) is compared in Table 3 . Results displayed that sunshine hour based models explained the highest portion of the solar global radiation variance out of all the tested approaches. Of the four models which use sunshine hours (Eqs. ((1-3),(8)), the exponential proposed method seems to explain the highest fraction $(99 \%)$ of $R_{G}$ variability, with a regression slope constrained through the origin, closest to unity. Even though the Angström-Prescott models, for first and third order, displayed very similar slope values, they are not accurate. The statistical predictors for these methods showed that on average $98 \%$ of the values were estimated with a deviation of less than $\pm 1 \mathrm{MJm}^{-2} \mathrm{day}^{-1}$ and their MPE's are among the lowest, under $1 \%$ and close together.

A special mention must be made regarding the AP model, second order, which also showed a regression coefficient and slope close to one, but with a deviation range that at least trebles the previous ones and the highest MPE. It has a remarkable tendency to underestimate solar radiation values throughout the entire period (Figure 2).

Models using daily extreme temperature or mean temperature values had similar regression slope line values, but the variability explained was much lower in comparison with Eqs. (1-3) and (8). Of the four temperature based approaches, the Allen model displayed the best performance, and explained, on average, $93 \%$ of the monthly $\mathrm{R}_{\mathrm{G}}$ variability, although the values were estimated with a root mean square of the order of $\pm 3.8 \mathrm{MJm}^{-2} \mathrm{day}^{-1}$. It must be noted from Figure 2 that Allen approach tended to overestimate the radiation values as also did the Annandale method. In fact, the performance of both models was almost identical since the altitude correction factor applied by Annandale, can be considered irrelevant for Buenos Aires.

Similar characteristics can be found when the performance of H\&S and García approaches are discussed. Both of them displayed similar MPE values, with $93 \%$ of the data estimated with a deviation range within $0.4-0.8 \mathrm{MJm}^{-2} \mathrm{day}^{-1}$. As $\mathrm{Li}^{\text {et }}$ al. [33] pointed out, the main common characteristic shared between Eqs. (4)-(7) is that they are directly and explicitly correlated with solar radiation and air temperature but implicitly include the influence of relative humidity by means of $\Delta \mathrm{T}$, which is linearly related to relative humidity, a parameter with high variability, difficult to measure accurately and hence a high potential error source. Despite the fact that according to analyses as Barry et al. and more recently Trnka et al. $[7,26]$, the temperature range is considered to be a poor predictor of $R_{G}$, it was found that Eqs. (3) - (7) performed fairly well for Buenos Aires. The difference in monthly average daily solar radiation for all approaches presented in Figure 3 can help to illustrate the temporal distribution of the mean monthly error over the entire analyzed period, supporting previous results and in addition, the model's systematic behaviour. The lower values of these differences can be attribute to AP (first and third order) and the exponential proposed estimations, with differences ranging in $\pm 6 \mathrm{MJm}^{-2} \mathrm{day}^{-1}$, while temperature based models presented a poorer agreement between observed and predicted solar radiation values, with differences reaching $\pm 14 \mathrm{MJm}^{-2}$ day $^{-1}$. 


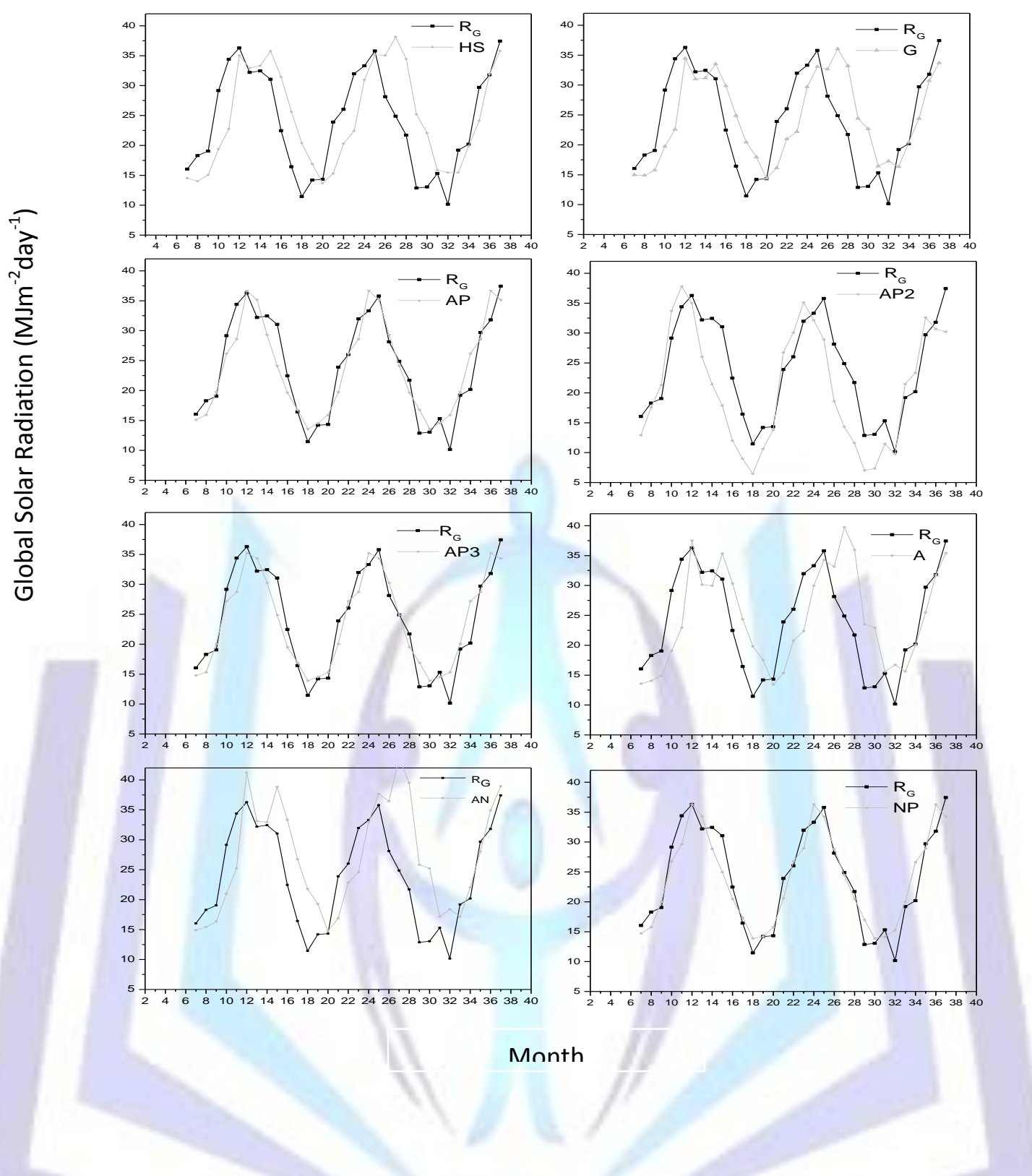

Figure 2. Comparison between measured and predicted values of solar global radiation, monthly mean for all tested empirical model and the new proposed.

Figure 3 can also contribute to infer some preliminary seasonal characteristic of the model's systematic behaviour. For those techniques based solely on temperature parameters, the highest differences appear in summer time, although in winter these can also be considerable. Furthermore, these monthly/seasonal variations fluctuate throughout each studied year, making an annual or seasonal pattern difficult to assess. 


\begin{tabular}{|c|c|c|c|c|}
\hline Methods & \multicolumn{4}{|c|}{ Regression Coefficients } \\
\hline & $a$ & $b$ & $c$ & $d$ \\
\hline H\&S & 0.14 & 0.39 & & \\
\hline García & 0.56 & 0.29 & & \\
\hline AP & 0.89 & 1.69 & 1.32 & \\
\hline AP2 & 0.45 & -1.0 & -55.45 & 18.58 \\
\hline AP3 & -18.67 & 56.32 & & \\
\hline A & 0.01 & 0.25 & & \\
\hline AN & - & 0.25 & -0.25 & \\
\hline NP & 0.21 & 0.62 & & \\
\hline
\end{tabular}

Table 2. Regression Coefficients of the model equations (1)-(8)

\begin{tabular}{|c|c|c|c|c|c|c|}
\hline Methods & $\mathbf{R}^{\mathbf{2}}$ & Pearson's $\mathbf{r}$ & Slope & MBE & RMSE & MPE(\%) \\
\hline H\&S & 0.93 & 0.96 & 0.94 & 0.80 & -0.19 \\
\hline García & 0.93 & 0.98 & 0.97 & 0.40 & -0.12 \\
\hline AP & 0.97 & 0.99 & 1.00 & -0.17 & 3.02 & -0.35 \\
\hline AP2 & 0.97 & 0.95 & 1.07 & -3.27 & 6.04 & -26.84 \\
\hline AP3 & 0.99 & 0.99 & 1.01 & -0.18 & -0.25 \\
\hline Allen & 0.93 & 0.96 & 0.95 & 0.60 & 3.81 & -0.94 \\
\hline Annandale & 0.92 & 0.96 & 0.94 & 0.60 & 6.84 & -0.90 \\
\hline New Proposed & 0.99 & 0.99 & 1.00 & -0.09 & 2.87 & 0.19 \\
\hline
\end{tabular}

Table 3. Coefficient of determination $\left(\mathbf{R}^{2}\right)$, Slope of linear regression including forced through the origin and statistical predictors of predicted against measured solar radiation data

If regression line forced through origin is replaced by standard linear regression for all the methods, the variability randomly increased and therefore performance decreased for all tested regressions. 


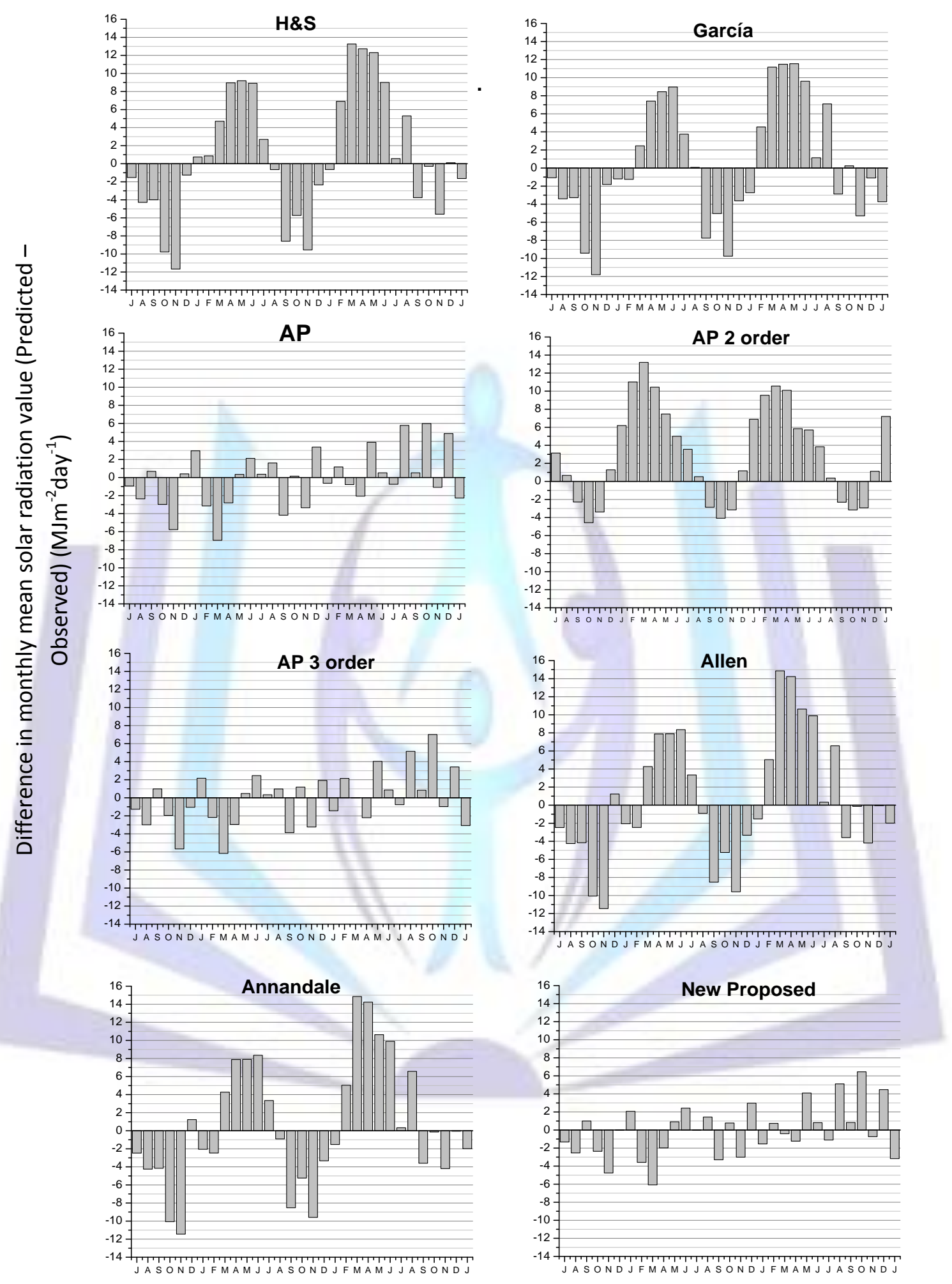

Months

Figura 3. Difference in monthly mean solar radiation for 2010-2013 in Buenos Aires for each proposed methods 
The annual distribution of the MBE, RMSE and MPE is shown in Figure 4, which illustrates the general trend of all methods. The results lend weight to the foregoing discussion regarding the statistical performance, indicating that deviation lower values are correlated with sunshine hour dependent models, with MPE values $\leq 1 \%$.

It is worth emphasizing that although the empirical methods proposed in Eqs. (1) -(8) involve only temperature and sunshine hour data, since the initial database contained pressure, humidity and wind values, as well as different meteorological models (not shown) involving these variables were tested; however, their regression coefficients barely reached values close to 0.5 ; hence they were discarded.

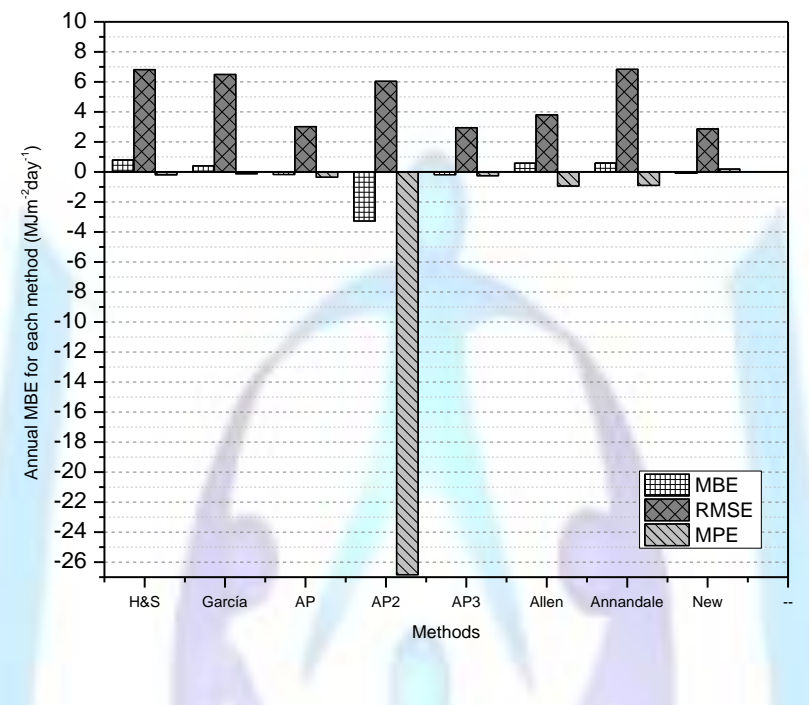

Figure 4. Annual values for statistical predictors for all the applied empirical approaches.

\section{Summary}

Solar radiation and its interaction with the atmosphere, is the driver and ultimate control of weather and climate. Hence understanding solar radiation throughout the planet is crucial to our understanding of the climate system and the changes it is undergoing. Given the various difficulties frequently encountered when measuring solar radiation a number of formulae and methods have been developed to estimate daily or monthly radiation, at different places. There exist a plethora of equations that have been published and tested making it difficult to choose the most suitable for a particular site. In this sense, eight methods for estimating monthly mean global solar radiation, were tested parameterizing the measured data in Buenos Aires. Explained variability, root mean square error, mean bias error and mean percentage error indicate that the highest precision was reached when sunshine duration was used as predictor. The PCs analysis confirms these results. The new exponential proposed method was found to be the best of the tested methods. It explained $99 \%$ of the RG variability with RMSE value, annual average, close to $2.9 \mathrm{MJm}-2$ day-1 and MBE less than 0.1 MJm-2day-1. With virtually equal accuracy, the Ångström-Prescott model, at first and third order, makes reliable estimations of the observed data, explaining on average $98 \%$ of the RG variability with similar values of RMSE and MPE. Figure 2 also reveals the lowest differences between estimated and observed values for these three approaches and underscores behaviours with no clear trends to underestimate (overestimate) the global solar radiation in Buenos Aires. Second order of Angström-Prescott type model did not have significant improvement on the accuracy of the estimation of global solar radiation: on the contrary the model outputs deteriorated.

If temperature values are the only available data, obtained results show that the explained variability of RG is also higher but the deviation range triples their values, with remarkable overestimation tendency in all the tested models. The inclusion of an altitude correction factor in these techniques did not improve their statistical performances as Annandale approach has revealed. Similar conclusions can be inferred when the models differ only by the N-weighting factor (number of cases) as is the case of García and Hargreaves-Samani methods. Both approaches have shown similar statistical predictor values, overestimating the predicted solar radiation. As was previously mentioned, the temperature based model implies considering the relative humidity and thus water vapour influence in their equations, yielding increasing sources of error due to the inherent variability of the parameter besides the difficulty to achieve accurate measures. Moreover, daily temperature amplitude range, which implies monthly amplitude, may also explain the poor performance gained in reproducing the interdependence between observed and predicted values. This amplitude may be related not only with relative humidity, but also with air pollution, as well as cloud cover percentage influencing the 
regression coefficients and the explained variability. Further investigations are necessary for replacing temperature (or combining with) with other meteorological parameters, as $\mathrm{RH}$, mixing ratio, dew point temperature or different kinds of associations.

\section{Acknowledgements}

The authors wish to thank the Pontificia Universidad Católica, Facultad de Ciencias Agrarias, to the Consejo Nacional de Investigaciones Científicas y Tecnológicas (CONICET) PIP 2004 5276, Universidad Tecnológica Nacional, Facultad Regional Haedo and Centro de Investigaciones Científicas y Técnicas para la Defensa (CITEDEF), PIDDEF 023/08.

\section{References}

[1] Gueymard CA. 2004. The sun's total and spectral irradiance for solar energy applications and solar radiation models. Solar Energy 76(4):423-53.

[2] Rivington M, Bellocchi G, Matthews KB, Buchan K. 2005. Evaluation of three model estimations of solar radiation at 24 UK stations. Agriculture and Forest Meteorology 132(3-4):228-43.

[3] Ball, R., Purcell, L., Carey, S., 2004, Evaluation of solar radiation prediction models in North America. Agronomy Journal 96:391-397.

[4] Stanhill G, Cohen S. 2001. Global dimming: A review of the evidence for a widespread and significant reduction in global radiation with discussion of its probable causes and possible agricultural consequences. Agriculture and Forest Meteorology 107: 255-278.

[5] Wild M, Gilgen H, Roesch A. 2005. From dimming to brightening: Decadal changes in solar radiation at earth's surface. Science 308: 847-850.

[6] Mishchenko MI, Geogdzhayev IV, Rossow WB, Cairns B, Carlson BE, Lacis AA, Liu L, Travis LD. 2007. Long-term satellite record reveals likely recent aerosol trend. Science 315( 5818): 1543-1543.

[7] Barry RG. 1992. Mountain weather and climate. USA, Methuen and Co. Ltd, 402.

[8] Liu DL, Scott BJ. 2001. Estimation of solar radiation in Australia from rainfall and temperature observations. Agricultural and Forest Meteorology 106 (1) p. 41-59.

[9]. Soltani A, Meinke H, de Voil P. 2004. Assessing linear interpolation to generate daily radiation and temperature data for use in crop simulations. European Journal of Agronomy 21 (2) :133-148.

[10]. Hansen JW. (1999). Stochastic daily solar irradiance for biological modeling applications. Agricultural and Forest Meteorology 94 (1): 53-63.

[11]. Richardson CW. 1981. Stochastic simulation of daily precipitation, temperature, and solar radiation. Water Resources Research 17(1): 182-190.

[12]. Wyser K, O'Hirok W, Gautier C, Jones C. 2002. Remote sensing of surface solar irradiance with corrections for 3-D cloud effects. Remote Sensing of Environment 80 (2): 272-284.

[13]. Nonhebel S. 1993. The importance of weather data in crop growth simulation models and assessment of climatic change effects. Ph.D. thesis. Wageningen Agricultural Uiiiversity, Wageningen, Netherlands.

[14]. Pinker RT, Zhang B, Dutton EG. 2005. Do Satellites Detect Trends in Surface Solar Radiation? Science 308 (5723): 850-854.

[15]. Supit I, van Kappel RR. (1998). A simple method to estimate global radiation. Solar Energy 63 (3):147-160.

[16]. Ehnberg J, Bollen SG, Math HJ. (2005). Simulation of global solar radiation based on cloud observations. Solar Energy 78(2):157-162.

[17]. Angström A. 1924. Solar and terrestrial radiation. Quarterly Journal of the Royal Meteorological Society 50:121-5.

[18]. Prescott JA. 1940. Evaporation from water surface in relation to solar radiation. Transactions of The Royal Society of South Australia 40: 114-118.

[19]. Bristow KL, Campbell GS. 1984. On the relationship between incoming solar radiation and daily maximum and minimum temperature. Agriculture and Forest Meteorology 31:159-166.

[20]. Thornton PE, Running SW. 1999. An improved algorithm for estimating incident daily solar radiation from measurements of temperature, humidity, and precipitation. Agricultural and Forest Meteorology 93 :211-228.

[21]. Weiss A, Hays CJ. 2004. Simulation of daily solar irradiance. Agricultural and Forest Meteorology 123 (3-4): 187199. 
[22]. Podestá GP, Nuñez L, Villanueva CA, Skansi MA. 2004. Estimating daily solar radiation in the Argentine Pampas. Agriculture and Forest Meteorology 123: 41-53.

[23]. Almorox J, Bocco M, Willington E. 2013. Estimation of daily global solar radiation from measured temperatures at Cañada de Luque, Córdoba, Argentina. Renewable Energy 60: 382-387.

[24]. Jiandong L, Jingmiao L, Linderholm HW, Deliang C, Qiang Y, Dingrong W, Shigenori H. 2012. Observation and calculation of the solar radiation on the Tibetan Plateau. Energy Conversion and Management 57: 23-32.

[25]. Geiger M, Lamissa D, Ménard L, Wald L. 2002. Controlling the quality of solar irradiation data by means of a web service, Geophysical Research Abstracts, European Geophysical Society 2. 2002.

[26]. Trnka M, Zdeněk Ž, Eitzinger J, Dubrovský M. 2005. Global solar radiation in Central European lowlands estimated by various empirical formulae. Agricultural and Forest Meteorology 131(1): 54-76.

[27]. Allen RG, Pereira LS, Raes D, Smith M. 1998. Crop evapotranspiration-Guidelines for computing crop water requirements. FAO Irrigation and drainage paper 56. FAO, Rome 300: 6541.

[28 ]Doorenbos J, Pruitt W. 1977. Guidelines for predicting crop water requirements. FAO Irrigation and Drainage Paper 24. FAO Rome, Italy.

[29] Hargreaves GH, Samani ZA. 1985. Reference crop evapotranspiration from temperature. Appl. Eng. Agric. 1:96-99.

[30] Linacre E. 1992. Climate data and resources. A reference and guide. Routledge. London-NY.

[31] Annandale JG, Jovanic NZ, Benade N, Allen Rg. 2002. Software for missing data error analysis. Penman-Monteith reference evapotranspiration. Irrigation Science 21(2):57-67.

[32] Almorox J. 2011. Estimating global solar radiation from common meteorological data in Aranjuez, Spain. Turkish Journal of Physics 35(1): 53-64.

[33] Li H, Fei C, Xianlong W, Weibin Ma. 2014. A Temperature-Based Model for Estimating Monthly Average Daily Global Solar Radiation in China. The Scientific World Journal. doi:10.1155/2014/128754.

\section{Author' biography with Photo}

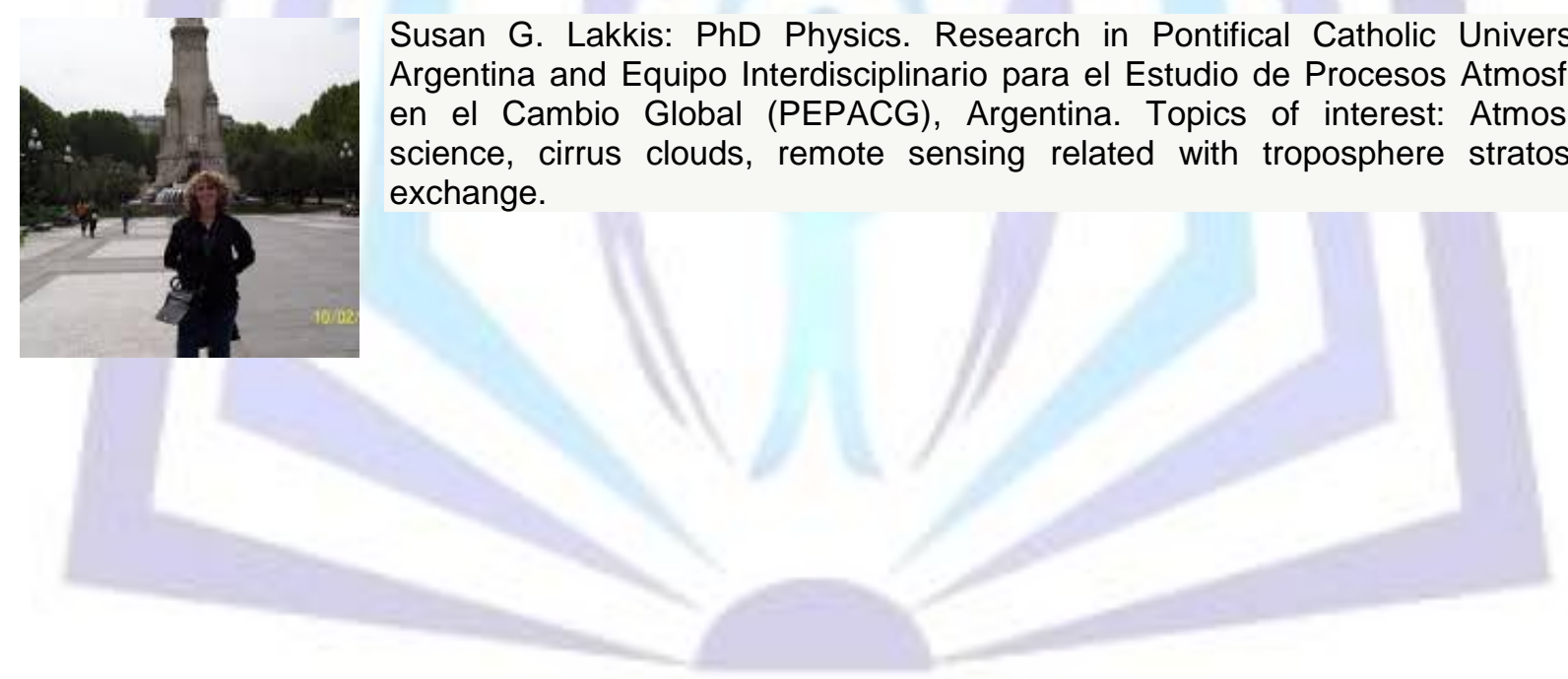

